\title{
Pierre Bourdieu: del rigor intelectual a la rigurosa subversión
}

JOAQUÍN RODRÍGUEZ LÓPEZ

Hace ahora seis años la RDTP acogía en sus páginas un artículo extenso titulado "Introducción a la antropología general de Pierre Bourdieu" cuyo propósito era vislumbrar el hilo conductor del exuberante, complejo y firmemente imbricado pensamiento y proyecto antropológico del profesor Bourdieu. Hoy, poco después de la casi simultánea publicación en español y francés de Meditations pascaliennes, es momento de retomar el hilo allí donde lo dejamos y ver qué facetas, qué dimensiones y qué rumbos ha seguido ese proyecto, y la ocasión es ahora propicia, sobre todo, porque Meditations pascaliennes, uno de sus últimos trabajos editados, es un compendio de más de cuarenta años de labor, una obra poderosa y abarcadora, un camino donde han llegado a cruzarse y fecundarse todos los saberes de las ciencias sociales hasta constituir una sola disciplina.

\section{UN PROYECTO UNIVERSALISTA PARA ESTABLECER LO UNIVERSAL}

Una salida: si los hombres han sacrificado ideales y vida por la invención de un vehículo, toma dicho vehículo para escapar de los cadáveres y acercarte a los ideales.

Karl Kraus (1992:131)

La fundación del suplemento literario y cultural Liber en el año 1989 respondía al deseo de "superar los provincianismos y los particularismos, tanto de las disciplinas y de las especializaciones como de las tradiciones y de las capillitas que se gratifican con la admiración mutua" lo que Bourdieu esperaba que contribuyera a "crear las condiciones para una libre circulación de las ideas, y así hacer posible un auténtico universalismo intelectual ${ }^{1}$. Los intelectuales, aquellos que se sitúan y actúan en el cam-

1 Liber, n. ${ }^{\circ} 1$, miércoles 11 de octubre de 1989, p. 2. Liber fue un suplemento europeo de libros cuyos seis primeros números fueron publicados conjuntamente por 
po de producción cultural ${ }^{2}$ y en el campo académico y que, por tanto, en contraposición al campo de poder económico, gozan de un sólido capital cultural y simbólico, están estructuralmente abocados a valorar, defender y propagar aquellos valores propios de la Skhole, es decir, el desapego, el distanciamiento, la pureza de la mirada, la defensa del conocimiento desafecto. El privilegio del intelectual es el de vivir en unas condiciones que le permiten desvincularse de las urgencias y los apremios de lo cotidiano para, de esa manera, al abrigo y lejos de las exigencias más perentorias y elementales, dedicarse a purificar su conocimiento de las cosas. Ocurre, sin embargo, como bien se sabe gracias a Bourdieu y la sociología reflexiva, que cuando se oculta consciente o inconscientemente el privilegio o la prerrogativa del intelectual, se acaba construyendo una teodicea de la propia condición y se acaba propagando una falacia epistemológica y política nefasta ya que se hace pasar por universal e igualitariamente repartida una forma de conocimiento que sólo surge, se anima y existe en unas condiciones históricas excepcionalmente particulares y precisas. La mirada distante y teórica sobre las cosas es al intelectual lo que el dinero es para quien ocupa posiciones en el campo económico y del poder, una garantía de mantener al margen la necesidad y sus urgencias. Pero si es cierto que el intelectual suele elevar a condición de juicio universal indiscutible lo que es fruto de la reflexión en unas condiciones particularmente favorables y desahogadas que no comparten sino unos pocos, no lo es menos que si se trabaja en la tarea y el proyecto de universalizar esas condiciones benéficas extremadamente particulares, se abren las puertas para que ese razonamiento y los frutos de ese razonamiento, hasta ahora excelsos y exclusivos, se generalicen, pierdan su rareza, se conviertan en un patrimonio compartido. No es tanto, por eso, que muchas de las más depuradas ideas y valores generados por los intelectuales sean falsos o carezcan de significación; no es que ese afán intrínseco de universalismo y universalización sea un impostor; se trata, más bien, de que lo universal y la aspi-

El País, Le Monde, Frankfurter Allgemeine, L'Indice y The Times Literary Supplement. Hoy, por razones que me son desconocidas y que, en cualquier caso, no trascendieron al público lector, se publica como suplemento de la revista Actes de la Recherche en Sciences Sociales.

2 En esta segunda entrega se obviará el volver a mencionar o explicar el significado de los conceptos acuñados por Bourdieu (campo social, habitus, capital, doxa, alodoxia y muchos otros) y se utilizarán en sus asociaciones y acepciones más corrientes. Para obtener una explicación en profundidad de cada uno de esos términos remito al lector a la primera parte de este artículo (RODRíGUEZ LóPEZ, 1993) o algunos de los textos más genéricos de Bourdieu: Esquisse d'une théorie de la pratique (Librairie Droz, Geneve, 1972, 270 p.) o El sentido práctico (Taurus, Madrid, 1991, 452 p.) 
ración a los valores más universales no surge, ni brota ni crece si no se universalizan las condiciones que hacen posible la búsqueda de lo universal, y la frase no es gratuita ni obedece solamente a una voluntad de prestidigitación verbal, sino que es la manera que utiliza Bourdieu normalmente para animar una reflexión y una vigilancia constantes sobre las condiciones que nos hacen decir y pensar las cosas como las decimos y pensamos, ejercicio epistemológico que él denomina socioanálisis. Si el intelectual aspira, por la posición que ocupa en el espacio social y por las condiciones que en él concurren, a los valores más universales, debe trabajar ahora de manera consciente para que se distribuyan lo más universalmente posible las condiciones que permiten querer y defender lo universal - lo bello, lo justo, la verdad, lo humano, lo cosmopolita-, porque realizar cualquier declaración de principios que no esté simultáneamente acompañada de una reflexión sobre las condiciones particulares que permiten a algunos anhelar y pretender esos principios es invocar en el vacío, clamar por un falso patrimonio supuestamente común de principios inalterables, exaltar lo inalcanzable para los más, lanzar salvas al aire y festejar el refinamiento propio, pero nunca proporcionar la posibilidad real a los demás de compartir ese patrimonio.

El proyecto cultural del Liber - libro y libertad, según alguna de sus acepciones en latín - trató de reforzar la conciencia intelectual sobre su dimensión internacional y universal, trató de entrelazar una verdadera red de intelectuales conscientes de su condición, de su fuerza colectiva y de su tarea común, y nada mejor para ello que un foro donde compartir libre y entrecruzadamente, sin los débitos y obligaciones que surgen de la pertenencia a las diferente capillas disciplinares o departamentales, libros, ideas y valores ${ }^{3}$. La mayoría de sus comentarios y artículos, que casi siem-

3 En parte de la entrevista que Pierre Bourdieu mantuvo con Jeanne Pachnicke, redactora del diario alemán Sonntag, sostenía: “-Usted habla de internacionalismo y de la internacional de los intelectuales. ¿Qué instrumentos ha desarrollado para construirla? He intentado aportar algo. Aunque me ha costado mucho trabajo. He iniciado, por ejemplo, un suplemento de un periódico que se llama Liber.. y que se publica internacionalmente en los mayores periódicos, Le Monde, Frankfurter Allgemeine Zeitung y Times Literary Supplement por ejemplo. Con este suplemento pretendo formar un círculo que construya los cimientos de una organización internacional. Deberá cumplir diferentes funciones. Una de ellas será la de ser un foro para intelectuales autónomos, donde puedan intercambiarse ideas. Y tiene también una función política. En el primer número hemos publicado, por ejemplo, el poema de un escritor rumano perseguido y amenazado y, al margen, hemos incluido una lista de nombres de poetas que, como él, están amenazados. Me dijeron que este simple hecho, el de ser nombrado en un periódico occidental, representó una protección. Algo más tarde pude saber que la situación de este poeta había variado, tras la aparición de esa contribu- 
pre eran reseñas de otros tantos libros aparecidos en distintos países y diferentes lenguas, insistían e indagaban en los problemas de la nacionalidad y el nacionalismo, del internacionalismo y el humanismo, del universalismo y del derecho universal a compartir los valores universales.

\section{El PARLAMENTO INTERNACIONAL DE ESCRITORES O LA INSTITUCIONALIZACIÓN DE LO UNIVERSAL}

"Cosmopolitas de todos los países, un último esfuerzo", así rezaba el cartel anunciador de la reunión del Parlamento Internacional de Escritores celebrada bajo el auspicio y apoyo del Consejo de Europa en marzo de 1997, en Estrasburgo, y uno de los ciclos de sesiones presidido por Jacques Derrida. Pierre Bourdieu, junto con el anterior y otros intelectuales franceses y del resto del mundo, fundaron y dieron cuerpo institucional a la idea, en el año 94, de una asociación en la que escritores de todo el mundo y diversa condición tomaran conciencia colectiva de su identidad, su posición en el campo social, su relación de fuerzas respecto a otros poderes, la cantidad y especie de sus capitales y la manera de utilizarlos en beneficio de la universalización de lo universal ${ }^{4}$.

Institucionalizar una relación a menudo esporádica y estrictamente personal, respondía al deseo de regularizar los encuentros y condensar las relaciones, de aglutinar los esfuerzos y orientar las decisiones, de

ción" (1991b: 28). Por mencionar desordenadamente algunos de los títulos de artículos aparecidos en números sucesivos de Liber que nos den una idea más cercana de sus intenciones, cabe destacar: ERIBON, D. "L'humanisme universel de Georges Dumézil", n. 16, decembre 1993; BeYNON, H. "E.P. Thompson et le socialisme humaniste", n. 16, decembre 1993; CADAT, B-Y. y ChERRIBI, O., "Nationalité et citoyennet: le cas néerlandais", n. 16, decembre 1993; GLOTZ, P., "L'internationalisme de Rosa Luxembrug", n. 13, mars 1993; Braselman, P. "Le meme droit pour tous?", n. 13, mars 1993; NoIRIel, G., "Comment reconnaitre a un étranger?", n. 13, mars 1993; Petrosino, D., "Citoyenneté et nationalité", n. 13, mars 1993.; BouRdieu, P., "La resonsabilité des intellectuels", n. 14, juin 1993; Kaldor, M., "Pour une solution pluri-ethnique au probleeme yougoslave", n.14, juin 1993.

4 Según la entrevista mantenida por Pierre Bourdieu con el diario El País en su suplemento Babelia el 30 de abril de 1994 con ocasión de la apertura de las sesiones del primero de los congresos, "Pierre Bourdieu es la fuerza motriz de una iniciativa internacional que se inscribe en una serie de pos. El mundo possoviético, el mundo posnorteamericano, el mundo posmoderno, y siempre un pre: el mundo que muchos desearían del futuro. La fuerza de los intelectuales, uncida por primera vez en la historia a un propósito que desborde el gran mercado de la posburguesía. Un parlamento mundial de la conciencia para combatir los Sarajevos de cada día" (p. 2) 
obtener del capital cultural y simbólico propio a los intelectuales los beneficios más rentables y, simultáneamente, más universalizables.

No es casualidad que el siguiente texto, escrito por Antonio Tabucchi y que podría ser suscrito por cualquiera de los integrantes del parlamento de escritores, se leyera en la ceremonia de apertura de las sesiones del año 97 cuando más arreciaba en Francia la campaña política del Frente Nacional. Un texto de otro escritor que es coherente con el espíritu del Parlamento: un lugar que es no tanto una sucesión de individualidades como el reconocimiento de una condición compartida y una conjunción de orientaciones y esfuerzos:

En este momento particularmente difícil, solamente algunas horas después de Auschwitz (si medimos el tiempo histórico con el metro del hombre cultura) [...], en este momento difícil, en el que las luciferinas ideas del nazismo, de la xenofobia, de la intolerancia, de la violencia, que han producido los hornos crematorios, parecen retornar, yo estoy en Estrasburgo con vosotros para afirmar con mi presencia de hombre y de escritor mi repulsión por estas ideas. [...] Porque me doy cuenta de que contra las tinieblas que nos amenazan a todos, los libros, como decía un poeta de mi país, son apenas una débil llama. Pero el hecho de que en cada país del globo del que venís, existan esas llamas, es ya algo. Prefiero las llamas que son nuestros libros a los grandes fuegos donde los libros y los hombres arden. La debilidad de nuestras llamas es para mi nuestra fuerza (Tabucchi 1997, citado en Weitzmann 1997).

Pero no se trató o no se trata tan sólo del reforzamiento de las relaciones entre los asistentes o de la explicitación de la conciencia intelectual sino, aún más, de la defensa de la libertad de creación frente a todo elemento heterónomo - de origen político o económico, sobre todo- que quiera someter la lógica autónoma de la creación artística e intelectual a principios ajenos y tergiversadores: no es sólo la defensa contra la más común y evidente de las injerencias, la política, la que utiliza diferentes tipos de censuras para detener o reconducir una vía cualquiera de experimentación o creación artísticas sino también, hoy más que nunca, la económica, que asumiendo diversas formas - subvenciones, donaciones, premios, fusiones y reagrupamientos empresariales, etc.- busca someter la autonomía del campo intelectual, del campo de creación cultural, mediante diversas formas de mercantilización insolente que acaben asimilando la lógica del campo de producción cultural a la lógica del campo de producción económico, a la lógica del mercado. Como ha dejado dicho Jacques Derrida, vicepresidente del Parlamento Internacional:

Las amenazas vienen de grupos, movimientos, Estados que cuestionan algo tan fundamental como el derecho a pensar y escribir libremente. Y también vienen 
del complejo mediático-intelectual que intenta introducir en la vida intelectual y en el espacio público la lógica del show-businness, la persecución cínica de la imagen a cualquier precio 5 .

Si como Bourdieu trató de demostrar en Las reglas del arte. Génesis y estructura del campo literario la constitución de un campo autónomo, con sus propios principios de legitimidad, fue una tarea heroica realizada al precio de subvertir y contradecir los valores económicos al uso, "estamos, en efecto, en un mundo económico al revés: el artista sólo puede triunfar en el ámbito simbólico perdiendo en el ámbito económico (por lo menos a corto plazo), y al contrario (por lo menos a largo plazo)" (Bourdieu 1995a:130). En términos más generales:

Tal vez hayamos dado aquí, para aquellos que lo están pidiendo, con un criterio bastante indiscutible del valor de cualquier producción artística y, más ampliamente, intelectual, a saber, la inversión en la obra que puede valorarse en función de los costos en esfuerzos, en sacrificios de todo tipo y, en definitiva, en tiempo; una inversión que va pareja, por ello mismo, con la independencia respecto a las fuerzas y a las imposiciones que se ejercen desde el exterior del campo o, peor aún, desde el interior, como las seducciones de la moda o las presiones del conformismo ético o lógico — con, por ejemplo, las problemáticas obligadas, los temas impuestos, las formas de expresión reconocidas, etc. (Bourdieu 1995a:133).

Cualquier complacencia o flirteo, por eso, con valores exageradamente comerciales, no sólo es un menoscabo de la obra que se preste a ello sino, también, un retroceso, una pérdida, una disminución de la autonomía del campo de producción artística y de los principios que lo constituyen ${ }^{6}$. Faltos de una estrategia de representación y reflexión colectiva, los investigadores están permanentemente expuestos a que sus comanditarios o entidades subvencionadoras acaben imponiéndoles el objeto de

5 La cita, aparecida en $E l$ País jueves 29 de septiembre de 1994, p. 34, continúa diciendo: «El filósofo Jacques Derrida propuso a sus compañeros dotar al Parlamento de total independencia y autonomía respecto de los poderes políticos, económicos, mediáticos y de todas las ortodoxias, para así poder inventar un nuevo espacio en la historia y en el mundon.

6 aLa lucha por la autonomía es sobre todo una lucha contra las instituciones y actores que en el interior del campo inducen a la dependencia respecto a las fuerzas económicas, políticas y religiosas, no importa si subordinan su producción a intereses económicos o, más sutilmente, lo sacrifican, como lo hacen los ensayistas, a la ley del éxito, o si sirven al establecimiento de relaciones privilegiadas con poderes externos (como el Estado o el Partido, todas las formas del estajanovismo) para erigir su dominio en el seno del campo" (Bourdieu 1991c: 53-54). 
la investigación, la problemática que han de tratar y el método con el que han de hacerlo?

La idea de la "red de ciudades refugio" para escritores perseguidos en sus países de origen es, evidentemente, una ayuda dedicada a paliar la más opresiva y directa de las coacciones, la política; la idea de desarrollar un "observatorio internacional de la censura" es, más bien, un centro de detección y denuncia de aquello que pretenda, como un caballo de Troya moderno, infiltrarse en el campo de creación cultural y contravenir los principios de la autonomía creativa.

Aunque Bourdieu fuera el impulsor del Parlamento Internacional - fiel a la idea de dotar a los intelectuales de un órgano de representación capaz de procurarse los instrumentos de reflexión y acción para preservar su autonomía y, con ella, la de los valores más universales fruto de la creación autónoma-, ciertas alusiones dispersas en sus últimos trabajos indican que "ha cesado de reconocerse en él" (1998b:8). Sólo cabe conjeturar cuáles han sido las razones de este desapego porque no ha existido declaración pública o escrita alguna que pueda aclararlo, pero el distanciamiento tiene que ver con las dificultes inherentes a la creación de un intelectual colectivo (1998b:7) y, parece ser, con un exceso de nacionalismo y de apego a los respectivos valores nacionales por parte de intelectuales que, al contrario, deberían haber respaldado y trabajado a favor de los valores más internacionalistas.

\section{EL EDITOR Y EL ESCRITOR (EL ARTISTA, EL INTELECTUAL) DE COMBATE}

Entre la cadena de acciones que Baudelaire emprendió para afirmar la independencia del artista destaca la elección de su editor:

Sabemos que, en una época en la que el auge de la literatura "comercial" hacía la fortuna de unas pocas editoriales grandes, Hachette, Levy o Larousse, Baudelaire prefirió asociarse, para Las flores del mal, con un editor pequeño, Poulet-Malassis, que frecuentaba los cafés de vanguardia: rechazando las condiciones económicas más beneficiosas y la difusión incomparablemente más amplia que le ofrecía Michel Levy, precisamente porque temía para su libro una divulgación excesivamente amplia, se compromete con un editor menor, pero a su vez comprometido con la

7 "Haría falta analizar, también, los efectos de los intercambios materiales y simbólicos que se instauran cada vez más a menudo entre las empresas y ciertas categorías de productores intelectuales a través de las demandas de intervenciones, expertise, consejos o conferencias, generosamente remuneradas, y todos los contactos formales o informales en el marco de misiones, comisiones, asociaciones o fundaciones" (BOURDIEU 1994: 25). 
lucha en favor de la poesía joven [...] y plenamente identificado con los intereses de sus autores (Bourdieu 1995a:107)

La conciencia oscura pero determinante, sin duda, de una afinidad estructural, de intereses, principios y percepciones estéticas, con un editor, es lo que llevó a Baudelaire a preferir la marginalidad como distintivo y garantía de autonomía e independencia, antes que la popularidad, que hubiera ganado tan sólo al precio de la masificación y vulgarización de los contenidos y al precio de perder lo mismo que le había servido para concebir ese contenido, la independencia. Aceptar otra cosa, en ese momento audaz en que sucesivos actos de afirmación y rechazo frente a los principios y el gusto de vida burgueses y al arte de vida burgués, hubiera sido desvirtuar lo más íntimo y propio de la condición que pretendía afirmar, la de artista:

Obedeciendo una de esas corazonadas profundamente deseadas e incoercibles a la vez, razonables sin ser razonadas, que son las "elecciones" del habitus ("en su editorial me editarán con honestidad y elegancian), Baudelaire instituye por vez primera la ruptura entre edición comercial y edición de vanguardia, contribuyendo así a hacer que surja un campo de los editores homólogo al de los escritores y, al mismo tiempo, la relación estructural entre el editor y el escritor de combate (Bourdieu 1995a:108)

No es por eso extraño que uno de los últimos números de Actes de la Recherche en Sciences Sociales estén dedicados a la edición y a los editores ${ }^{8}$ :

[...] el editor es, de esta manera, un personaje doble que debe saber conciliar el arte y el dinero, el amor a la literatura y la búsqueda del beneficio mediante estrategias que se sitúan en alguna parte entre esos dos extremos, entre la sumisión realista o cínica a las consideraciones comerciales y entre la indiferencia heroica o insensata a las necesidades económicas (Bourdieu 1999a:16)

La desvirtuación del editor, por tanto, de ese intermediario cultural encargado de difundir y promover un tipo de discurso particular sobre la realidad, viene cuando la balanza se inclina excesivamente del lado de los intereses descarada y desnudamente comerciales, no porque la persecución obstinada del beneficio económico pueda calificarse de ilegítima en sí misma, sino porque los principios sobre los que se construyó la independencia del campo editorial y literario se ven usurpados o sustitui-

${ }^{8}$. Actes de là Recherche en Sciences Sociales, Edition, Editeurs, n. ${ }^{\circ}$ 126-127, mars 1999, Seuil. 
dos por principios ajenos y heterónomos que subvierten los intereses propios del campo al imponer los del cálculo y el interés económico a corto plazo en detrimento de las editoriales que asumen el riesgo inherente a las apuestas culturales y artísticas a largo plazo. La denominada "revolución conservadora en la edición" es, por eso, una llamada de atención sobre las muchas veces inadvertida pero penetrante injerencia de principios propios de una lógica financiera y comercial sin concesiones en el campo de la edición, en un campo construido sobre el amor al arte, es decir, sobre una forma de cálculo cuya premisa es la ignorancia de la presión mercantil y la concentración sobre la lógica de la creación. El consagrar muchos de sus últimos trabajos a "defender la libertad del arte en relación al dinero" y, particularmente, el papel que el editor debe jugar en ello ${ }^{9}$, es lo mismo que intentar salvaguardar lo más arriesgado, vanguardista, distinto y variado, "defender las conquistas, intrínsecamente internacionales e internacionalistas, de toda la historia acumulativa de la literatura" (Bourdieu 1999a:26) en contra de las fuerzas homogeneizadoras, igualadoras y uniformizantes de una edición desvirtuada: los pequeños autores y editores nunca, ni ayer ni hoy, han gozado de un peso específico importante respecto al conjunto de las posiciones que pueden ocuparse en el campo editorial, sin embargo su presencia es estrictamente necesaria porque encarnan el principio mismo de existencia de ese campo, el amor al arte, la renuncia expresa a trabajar orientando la producción a recompensas materiales inmediatas, principio sin el cual el campo editorial dejaría de ser tal para pasar a ser, descaradamente, campo económico, campo comercial. Asegurarse la existencia del pequeño editor es lo mismo que luchar por salvaguardar la diversidad y libertad de la creación, defender la heterogeneidad de los mensajes y las vías de exploración y ensayo alternativas, huir del adocenamiento y de los modelos de la industria del entertainment y apostar por la evolución y cambio continuo de sus contenidos, porque son los nuevos editores los que aseguran la circulación y el movimiento mismo dentro del campo literario al enfrentarse a los conglomerados editoriales más conservadores.

El proyecto mismo de Liber-Raisons d'agir, acogido dentro de la colección Liber de la editorial Seuil, recientemente lanzado, responde a la

9 "De hecho, mientras que haya representantes para sostener a las pequeñas editoriales, pequeños editores para publicar a jóvenes autores desconocidos, libreros para proponer y promover los libros de los jóvenes escritores publicados por las pequeñas casas, críticos para descubrir y defender a los unos y a los otros, sobre todo a las mujeres, el trabajo sin contrapartida económica, realizado por amor al arte, por el amor al arte, seguirá siendo una inversión realista que recibirá un mínimo de reconocimiento material y simbólico", en Actes de la Recherche en Sciences Sociales, 126-127: 26. 
idea de que "el libro está en condiciones de oponerse al monopolio de los medios de comunicación sobre el gran público" (Bourdieu 1997a:40).

Yo quisiera - apunta Bourdieu-, y este es el aspecto más ambicioso del proyecto, que la serie de pequeños libros, que se presentarán cada vez con un color diferente, constituyan poco a poco una suerte de enciclopedia (en el sentido del siglo XVIII) popular e internacional donde los ciudadanos encuentren las armas (ofensivas y, sobre todo, defensivas: yo comparo a menudo a las ciencias sociales con deportes de combate como el judo) para afrontar el mundo contemporáneo, para comprenderlo, criticarlo y, eventualmente, trabajar para transformarlo. Intentaremos, en cada ocasión, proponer líneas de acción y, algunas veces, medidas concretas (Bourdieu 1997a: 40) ${ }^{10}$.

Organizar la resistencia contra las fuerzas del mercado para salvaguardar espacios de creación, pensamiento y libertad o, mejor dicho, para establecer las condiciones necesarias para que la creación, el pensamiento y la libertad puedan desarrollarse sin coacciones externas, es el denominador común de los proyectos de Liber, del Parlamento Internacional de Escritores y de la colección Raison d'Agir. Más allá de la aparente heterogeneidad y multiplicidad de sus proyectos, una vez más, todas las iniciativas están estrechamente imbricadas y se soportan y alientan mutuamente.

\section{LA DEMOCRACIA NECESITA SOCIOLOGÍA}

Los Estados democráticos son o deberían ser aquellos que garantizan el acceso, el disfrute y el ejercicio universal, a través de diversos tipos de instituciones y medidas, a los bienes y valores poseídos, producidos y generados por el país o la sociedad y, en primer lugar y sobre todo, al uso y ejercicio mismo de la opinión y el juicio políticos. La institución encargada de cimentar, formar y desarrollar esa clase de juicio especializado es la escuela, la educación, pero no siempre es capaz de lograrlo:

10 Los primeros títulos que forman parte de la colección dirigida por Bourdieu son: Méditations pascaliennes, de Pierre BOURDIEU; La paix de religion, l'autonomisation de la raison politique au XVI siecle, de Olivier CHRISTIN; Pour Albertine. Proust et le sens du social, de Jacques DuBoIs; En quéte de respect, de Philippe Bourgeors; Sur la télévision, de Pierre BOURDIEU; Quelques diagnostics et remedes urgents pour une université en péril, ARESER; Les nouveaux chiens de garde, de Serge HALIMI; Le décembre des intellectuels francais, de Julien Duval, Christophe GAUBERT, Frédéric LEBARON y Dominique MARCHETTI; y, por último, Contre feux. Propos pour servir la résistance contre l'invasion néo-libérale, de Pierre BOURDIEU. 
Las condiciones económicas y culturales de acceso a la opinión política deben democratizarse y hacerse genéricamente disponibles. La educación ocupa en esto una posición determinante, la básica y la continua. No es tan sólo precondición para el acceso a un puesto de trabajo o a una posición en la sociedad: es la condición principal para el ejercicio real de los derechos de los ciudadanos (Bourdieu 1998a:2).

No basta, como ya dejó establecido Bourdieu en otro de sus trabajos (1985), con esgrimir la falacia del comunismo lingüístico, con argumentar que hablar significa lo mismo que ser escuchado, que tener voz y voto, que manifestar una opinión sólidamente fundada y con visos de ser tomada en cuenta. Hablar es una capacidad universalmente repartida pero, para que se convierta en juicio competente y fundamentado, debe haber gozado previamente de unas condiciones favorables que transformen la mera expresión de puntos de vista apegados a las realidades y necesidades más cercanas en opiniones políticas más cimentadas y globales. Los grupos más desfavorecidos del espacio social, más sujetos a las precariedades materiales, culturales y simbólicas, tienen suficiente con intentar hacer frente a las urgencias cotidianas, con solventar los aprietos del vivir diario, de forma que su juicio es tan limitado como las condiciones sobre las que se basa, su indefensión pública y simbólica tan grande como sus carencias privadas, de manera que el ejercicio activo y juicioso de un supuesto derecho o garantía universales es una mera ficción. Si el juicio político se caracteriza por ser capaz de ofrecer una visión global o comprehensiva sobre determinados acontecimientos sociales, también es cierto que para ser global ese juicio necesita haber madurado en unas condiciones materiales $y$ culturales que propicien el desapego, la distancia, la ecuanimidad, la perspectiva, la comparación, valores todos que escapan a un raciocinio sometido a la presión de la escasez y la necesidad.

Más manipulada todavía, la opinión más precaria anda siempre dividida entre dos extremos, es objeto de deseo de dos posiciones antagónicas pero igualmente interesadas en decantar la opinión popular de su lado: la de la arrogancia tecnocrática, actualización del despotismo ilustrado, que desea supuestamente lo mejor para el pueblo aún en contra de su voluntad, y la complacencia o condescendencia de los demagogos y populistas, que atienden a la opinión popular siempre que mejore las cuotas de popularidad o haga repuntar las curvas de intención de voto. Nada contribuye, por más que las repetidas declaraciones de intenciones así lo manifiesten, a proporcionar las condiciones reales que permitan a la más debilitada y chata de las opiniones tomar distancia sobre la realidad más cercana para formar un juicio más ponderado sobre ella. Max Weber ya sabía esto: la kadijustiz, o justicia del cadi, empleada y administrada en 
sociedades poco complejas, era una justicia basada sobre un sentimiento espontáneo de equidad material, justicia que no elevaba a regla o categoría el resultado de una polémica sino que dirimía y se aplicaba en cada ocasión como si se tratara de una ocasión nueva; la justicia impartida y practicada en las sociedades complejas y avanzadas no podría seguir este modelo a riesgo de perderse en meandros interminables. Generar un corpus legislativo abstrayendo los rasgos repetidos y generales de los casos, es la manera elegida para dar respuesta a su número y multiplicidad, pero ese esfuerzo de abstracción y distanciamiento requiere de unas condiciones muy particulares.

El juicio, el sentido de la justicia, la opinión de los grupos sociales material y culturalmente más desfavorecidos, es una derivación de la escasez y la precariedad: en esas circunstancias, en las que la contabilidad o el ahorro carecen de sentido porque, simplemente, no hay nada que sacrificar en el presente para dárselo a un supuesto e irreconocible futuro, se observa una suerte de materialismo práctico o espontáneo que tiñe todas las acciones de esos grupos. El sentido de la justicia o el juicio sobre cualquier situación que les pueda atañer adolece de la inmanencia e inmediatez propias de las condiciones en que se forma el juicio. Es decir, ese juicio no comprende, considera o valora un problema en términos propiamente políticos porque la política es a la opinión lo que la justicia formal es a la justicia del cadi, un ejercicio de abstracción y distanciamiento impropio de quien no reúne las condiciones para practicarlo.

Bourdieu había escrito ya antes mucho sobre este asunto. En La distinción había dicho:

Aunque al pueblo idealizado se le atribuya un conocimiento completamente práctico, si no del mundo social como tal, al menos de su posición y de sus intereses en ese mundo, aún quedaría por examinar si y cómo, ese sentido político puede expresarse en un discurso conforme con la verdad que encierra en estado práctico y convertirse de ese modo en el principio de una acción consciente y, mediante el poder de movilización que encierra la explicitación, realmente colectiva; o, para permanecer más cerca de la realidad, si constituye verdaderamente esa especie de intuición infalible en que a veces se le ha transformado y que permitiría, al menos, reconocer en el mercado de los discursos producidos y ofertados por los poseedores de instrumentos de producción de problemas y opiniones legítimas, los productos más apropiados (Bourdieu 1988: 406)

En los últimos tiempos, en la década de los 90, con la disolución paulatina de los progresos y ganancias obtenidas por las "sociedades del bienestar" ante el acoso del liberalismo económico más rampante, Bourdieu retoma los argumentos anteriormente desarrollados en vista de la necesidad de armar a la sociedad de una serie de elementos de juicio y crite- 
rios de reflexión que les sirvan para enfrentarse en mejores condiciones al cruce indiscriminado y confuso de argumentos políticos. No en vano, una de sus últimas obras lleva por título Contrafuegos: palabras para servir a la resistencia contra la invasión neo-liberal (1998b). La cuestión es, por tanto, que a la sociología le queda reservado un papel esencial y vigilante en las democracias modernas: desvelar continuamente la falacia que insiste en atribuir una opinión política formada a los que no tienen la posibilidad de tenerla; resistir al populismo y al tecnocratismo, pares en su manipulación de la opinión; proporcionar los medios de forma realista para que los ciudadanos tengan la oportunidad de ejercer verazmente sus derechos; reflexionar sobre la manera en que todas las personas puedan acceder à los valores más universales fruto de la historia de la civilización occidental; "volver hacia atrás para observar los determinantes socioeconómicos reales y verdaderos de las incontables heridas infringidas a la libertad de las personas, a sus legítimas aspiraciones de felicidad y desarrollo personal" (Bourdieu 1998a:3).

Existe como un anhelo de universalidad en todas las iniciativas teóricas y prácticas llevadas a cabo por Bourdieu, más explícitas o patentes y publicitadas ahora que en tiempos anteriores. No se trata de un universalismo basado en la ética comunicacional de Habermas o de cualquier otra forma de hermenéutica ${ }^{11}$, porque todas esas corrientes escamotean una cuestión decisiva y molesta: las condiciones sociales y económicas, escolares especialmente, necesarias para acceder a una clase de opinión, la política, que es un discurso articulado y coherente sobre el mundo social. Buena parte de las Meditaciones pascalianas son una diatriba contra ese olvido, unas veces explícito y consciente, fruto de la manipulación política directa, otras veces resultado de esa falta de vigilancia reflexiva que deben ejercer los científicos sociales sobre su posición y sus opiniones y que, indirectamente, provoca efectos políticos:

Es suficiente retornar al espacio público tal como es en realidad para comprender que la ilusión epistemocéntrica que lleva a hacer de la universalidad de la razón y de la existencia de intereses universalizables el fundamento de un con-

11 "Me parece, en efecto, que, cerca del efecto característico de la filosofía alemana tal como la describía Marx, Habermas hace sufrir a las relaciones sociales una doble reducción o, lo que viene a ser lo mismo, una doble despolitización conducente a rebajar, sin que lo parezca, la política al terreno de la ética: reduce las relaciones de fuerza política a relaciones de comunicación (y a la "fuerza sin violencia de los discursos argumentativos que permiten realizar el entente y suscitar el consenso"), esto es, a relaciones de diálogo de donde ha evacuado prácticamente las relaciones de fuerza que se realizan bajo una forma transfigurada" (Bourdieu 1997b: 81). 
senso racional, encuentre su principio en la ignorancia (o en el rechazo) de las condiciones de acceso a la esfera política y a los factores de discriminación (como el sexo, la instrucción o los ingresos) que limitan las oportunidades de acceso no solamente, como se dice mucho, a propósito de las mujeres sobre todo, a posiciones en el campo político sino, más profundamente, a la opinión política articulada ("opinar [doxazein], es hablar", decía Platón) y, de ahí, al campo político (Bourdieu 1997b:81-82)

La democracia necesita sociología, la democracia necesita la vigilancia y consejo de una ciencia que le recuerde constantemente que para ser lo que pretende necesita que la ejerzan y utilicen, necesita de la opinión de los ciudadanos y necesita ser, sobre todo, consciente de que ni la opinión ni el uso suceden espontáneamente sino que son el resultado de un aprendizaje largo en unas condiciones sociales y económicas determinadas que debe encargarse de hacer accesibles a todos por igual.

No se trata de la restitución de un Estado vigilante o chauvinista sino de un Estado garante y tolerante, de la defensa de una organización y un espacio de ámbito nacional o, mejor aún, internacional, de la "creación de un Estado social europeo que acumule las adquisiciones sociales más avanzadas de los diferentes Estados nacionales (más guarderías infantiles, escuelas, hospitales y menos ejército, policía y prisiones) y subordine la puesta en práctica del mercado unificado a la elaboración de medidas sociales destinadas a compensar las consecuencias sociales probables que la libre competencia puede ocasionar a los asalariados" (Bourdieu 1998d:73). En otras palabras:

Esta defensa del Estado no se inspira en el nacionalismo. Si por una parte luchamos contra el Estado nacional, hace falta defender las funciones "universales" que cumple y pueden ser satisfechas también, si no mejor, por una Estado supranacional (Bourdieu 1998c:47)

\section{LOS «ESCRITOS DE COMBATE»}

En una entrevista mantenida con el artista alemán Hans Haacke, Pierre Bourdieu sacaba a la luz una de las contradicciones que está en la base de toda producción científica, especialmente la de las ciencias sociales, que debería servir, en buena medida, a aquellos que no la entienden ni la pueden utilizar:

Sucede lo mismo en ciencias sociales. Se dice siempre: eso está muy bien, pero la gente a la que su sociología podría servir, no la lee; y aquellos que la leen se sirven de ella a menudo, pero para hacer mejor eso mismo que usted pretende 
evitar. Esta es una contradicción muy profunda. No se pueden utilizar a la vez lenguajes que suponen años y años de acumulación (el lenguaje artístico que usted emplea presupone toda la historia del arte, al menos después de Duchamp...) y ser accesible a primera vista, aun cuando el mensaje [...] (Bourdieu 1994:109).

Es seguramente ese deseo por superar la contradicción, por contrarrestar el esoterismo inherente a la producción científica y acercarse a quienes más la necesitan, lo que ha llevado a Bourdieu a embarcarse, al menos desde el año $1993^{12}$, en una serie de trabajos, proyectos, intervenciones públicas y declaraciones que sobrepasan lo estrictamente académico - por muchas y evidentes implicaciones políticas que cada investigación pudiera haber tenido- para enrolarse en la defensa de lo público y en la lucha política. No se trata, claro, de una implicación inconsciente o escasamente meditada: Bourdieu aporta, por una parte, afinadas herramientas de análisis puestas a prueba durante cuarenta años de trabajo y, también, el prestigio adquirido como intelectual, el capital cultural y simbólico acumulado durante todo este tiempo por ocupar la posición que ocupa en ese campo intelectual, dominado entre los dominantes. Aunque esta interpretación no pueda ser otra cosa que personal e inferida, porque no existe ninguna entrevista o declaración personal que la atestigüen, no parece que el paso al cuerpo a cuerpo político, al enfrentamiento con determinados elementos del campo del poder, se haya hecho sin dolor y sin renuncias calculadas ${ }^{13}$. Tres son al menos las resistencias que han debido vencerse: frente a los obreros, frente a los poderosos y, de paso, frente a los propios intelectuales. Cara a los primeros porque los intelectuales, conscientes de la distancia insalvable que separa a unos y a otros, han preferido rebajar sus competencias y degradar su condición para aminorar así su complejo de culpa ${ }^{14}$; cara a los segundos porque, domi-

12 Año de la publicación de La miseria del mundo.

13 "No tengo mucha inclinación por las intervenciones proféticas y desconfío siempre de las ocasiones donde pueda ser arrastrado por la situación o las solidaridades a ir más allá de los límites de mi competencia. No me habría comprometido en la toma de posiciones públicas si no hubiera tenido, cada vez, el sentimiento, puede ser que ilusorio, de estar forzado por una suerte de furor legítimo, próximo algunas veces a algo como un sentimiento de deber. El ideal de intelectual colectivo, al que he intentado conformarme siempre que he podido encontrarme con otros a propósito de tal o tal punto particular, no siempre es fácil de realizar" (BOURDIEU 1998b: 7).

14 "Muchos intelectuales han ofrecido su competencia como sacrificio a la clase obrera, se han puesto a sus pies. ¿Por qué ha cometido el proletariado, entonces, tantos fallos? Bien porque los intelectuales les han impuesto sus propias concepciones - utópicas, idealistas, etc.- bien -y este es tan sólo el fallo opuesto- porque han entregado como ofrenda al proletariado su conocimiento, su sabiduría y su com- 
nados entre los dominantes, muchos intelectuales desean compensar esa carencia, superar ese complejo ahora a la inversa, acumulando la clase de capital de la que carecen aunque sea a costa de olvidar y obviar la especificidad de sus competencias: en vez de perseverar en lo más propio de la condición del intelectual —operar y crear al margen de las fuerzas económicas, políticas y religiosas para preservar su autoridad específica-, prefieren sacrificar sus competencias poniéndolas al servicio de los campos que mejor les compensen en otras especies de capitales. De ahí la sucesión de fast-thinkers televisivos ${ }^{15}$, del periodismo de reverencia practicado por periodistas entregados a grupos industriales y financieros ${ }^{16}$, de ensayistas frívolos y hueros que, parafraseando a Karl Kraus, viven del tema y mueren con él ${ }^{17}$; frente a sí mismos porque deben llegar a cobrar conciencia de que su influencia específica será tanto mayor cuanto más se ahonde en lo más específico de la condición recuperando los valores que Emile Zola puso en el J'accuse, la introducción de una política de la pureza intelectual en el universo propiamente político.

Definir claramente cuál es hoy la función del intelectual es congruente con la posición de Bourdieu en la década de los $90{ }^{18}$ :

Pienso que los intelectuales deben aprender a ser críticos frente a sí mismos, criticarse a sí mismos como intelectuales y ser capaces de expresar la situación de los otros grupos sociales, por lo menos entenderles y, tal vez, en ocasiones favorables, ayudarles a expresarse. Los trabajadores, por ejemplo, tienen mucho que decir, pero, a menudo, carecen de los instrumentos, de los medios de expresarlo, de explicitarlo. Y ahí reside la tarea principal del intelectual en esa

petencia como forma de reconocimiento de la culpa. Se han hecho voluntariamente más estúpidos de lo que eran. Existe un texto famoso de Pascal que dice: Cuando queráis haceros creyentes, debéis haceros más estúpidos" (BOURDieu 1991b: 19).

15 Sobre la televisión. Léase el epígrafe titulado "La urgencia y el fast thinking", pp. 38-40.

16 Léase el libro publicado en la colección Liber Raisons d'agir titulado Les nouveaux chiens de garde (HALIMI, 1997).

17 "Lo que vive del tema, muere con él. Lo que vive en el lenguaje, vive con él" (KraUS 1990: 198).

18 Bourdieu cita a menudo un texto de Wittgenstein en el que, además, se conmina a la filosofía, a la ciencia social, a ser algo más que una jerga especializada: "¿Qué interés hay en estudiar la filosofía, si todo lo que hace por uno es volverlo capaz de expresarse de manera relativamente plausible sobre ciertas abstrusas cuestiones de lógica, etcétera, y si eso no mejora su modo de pensar las cuestiones importantes de la vida de todos los días, si eso no lo hace más consciente que un periodista cualquiera en la utilización de las expresiones peligrosas que la gente de esta especie emplea para sus propios fines? (WITTGENSTEIN, en BOURDIEU 1997b: 53) 
relación: asistir en la explicitación, proporcionar ayuda en la expresión (Bourdieu 1991b:16-17)

Efectivamente, y por comenzar mencionando la mayor de ellas, $L a$ miseria del mundo (1999) es una obra monumental, tanto en intenciones como en extensión: su cometido y empeño es, precisamente, dar voz a aquellos que padecen las grandes o pequeñas miserias de la vida cotidiana -emigrantes, habitantes de los suburbios, poblaciones marginales, empleados de las escalas profesionales más bajas, funcionarios, profesores de escuela, etc.-, a causa de las que sufren y padecen y a las que no saben o no pueden dar expresión o forma. Como ya había declarado en otro lugar, la sociología debe ser la ciencia vigilante que ayude al ciudadano a ejercer con garantías su derecho a la felicidad y la realización personales y, desde luego, desvelar cuáles son los determinantes socioeconómicos o de otra especie que frustran permanentemente sus anhelos y sus expectativas ${ }^{19}$. Es una equivocación estimar que sólo las grandes miserias o calamidades requieren ser pensadas: más bien al contrario, si bien en las sociedades occidentales ha retrocedido la-indigencia extrema y el sufrimiento sin consuelo, se han multiplicado los espacios -en el sentido físico y sociológico- en los que la subordinación, dependencia y apartamiento son tan abrumadores que el vivir cotidiano puede convertirse en una dura tarea. No podemos negar a la sociología que convierta las miserias cotidianas en un objeto de pensamiento central porque comprender los sufrimientos más aparentemente ínfimos de las personas anónimas es, a la vez, comprender las grandes contradicciones y fallas políticas, sociales y económicas.

Por La miseria del mundo pasean los emigrantes magrebíes de primera y segunda generación que habitan en Francia: los primeros en la ilusión permanente de un retorno indefinidamente diferido, ni ciudadanos plenamente integrados en el país de adopción ni completamente originarios, ya, del país que abandonaron y, los segundos, desdoblados permanentemente, oriundos imaginarios del país de sus padres en una nación

19 No es una coincidencia que Bourdieu apoyara públicamente, reconociendo que ahora, al menos, no se sentía tan sólo, el libro de Viviane FORRESTER (1996), un enorme éxito editorial que generó una polémica bastante cruda en el año 96 y que en España quedó desatendido y sin repercusión. Su trabajo comienza diciendo "Vivimos en medio de una falacia descomunal: un mundo desaparecido que nos empeñamos en no reconocer como tal y que se pretende perpetuar mediante políticas artificiales. Millones de destinos son destruidos, aniquilados por este anacronismo debido a estratagemas pertinaces destinadas a mantener con vida para siempre nuestro tabú más sagrado: el trabajo" (p. 9). 
que les niega los derechos reales de la plena ciudadanía; se encuentran, también, los franceses habitantes de los suburbios, descorazonados, desmoralizados, forzados a convivir con las poblaciones de emigrantes en barrios devaluados, desatendidos, olvidados, en los que, antes de llegaran estos últimos, habían invertido su dinero y su ilusión; pasean los funcionarios encargados por el Estado de mantener la paz social, policías, trabajadores sociales, profesores y médicos, forzados a suplir con una voluntad y una entrega permanentemente traicionadas la dimisión y retirada del Estado, encargado, teóricamente, de reforzar y mantener los lazos de cohesión social ${ }^{20}$; se pronuncian, igualmente, los parados, los hombres y mujeres que invirtieron toda su ilusión, es decir, su illusio, en una labor, en un trabajo, en un proyecto en el que se implicaban vida y dedicación y que, ahora que el trabajo no vale nada, son incapaces de comprender a qué destinaron sus esfuerzos y en qué malgastaron sus vidas; se dan cita, también, los estudiantes que, tras conseguir los títulos que supuestamente les acreditaban para alcanzar lo que prometían, deben asumir lenta y dolorosamente que sus títulos están devaluados y poco pueden esperar recibir a cambio, un futuro vital y profesional tan desvalorizado como los títulos conseguidos; encontramos, además, a aquellos supuestamente afortunados que, habiendo conseguido una posición, se ven forzados por la precariedad y la inconsistencia de los empleos a practicar un sucedáneo de la profesión que pensaron y desearon, a acceder al despotismo y a convenir tácitamente con la explotación...

Toda la obra es un ejercicio de compaginación, fusión y mutua sustentación entre la reflexión teórica y las entrevistas directas a los protagonistas implicados. La exposición meditada del significado de lo hablado precede siempre a la charla posterior aunque, paradójicamente, haya sido escrita una vez que se mantuvo la entrevista. Como sugiere la mayeútica socrática, Bourdieu y todos los participantes en esta obra gigantesca - Rosine Christin, Patrick Champagne, Löic J. D. Wacquant, Abdelmalek Sayad, etc. - se esfuerzan por ayudar a que la palabra de sus interlocutores fluya sin los silencios y resistencias que suelen imponer las situaciones desiguales de comunicación, por acompañarles en la formulación progresiva y paulatina de sus pensamientos hasta ese momento

20 "Estos agentes estatales están atravesados por las contradicciones del Estado, que muchas veces viven, en lo más profundo de sí mismos, como dramas personales: contradicciones entre las misiones, a menudo desmesuradas, que se les confían, particularmente en materia de empleo y vivienda, y los medios, casi siempre irrisorios, que se les entregan: contradicciones — sin duda las más dramáticas- producidas, en parte, por su acción, como las resultantes de las esperanzas y desesperaciones suscitadas por la institución escolar" (BOURDieu 1999b: 164) 
no verbalizados y, por tanto, escasamente racionalizados, por no imponer previamente tema o problema alguno que, enunciado a la manera que suele hacer el periodismo, acaba imponiendo el problema que dicen que existe y la manera misma de enunciarlo ${ }^{21}$.

Aunque es arriesgado sugerir que en un párrafo caben todas las intenciones de esta obra, sí puede servir el siguiente para tener presente el impulso que la sostiene:

Si me pareció necesario evocar una de las series causales que llevan desde los lugares más centrales del Estado hasta las regiones más desheredadas del mundo social, y hacer hincapié, al mismo tiempo, en la dimensión propiamente política de los procesos, sin duda infinitamente más complejos, que condujeron a un estado de cosas en realidad nunca pensado ni querido por nadie, no es para hacer un sacrificio a la lógica de la denuncia y el juicio, sino para tratar de brindar posibilidades a una acción racional que apunte a deshacer o rehacer lo que la historia ha hecho (Bourdieu 1999b:166)

Tratar todos los temas y situaciones mencionadas no tendrían nada de especialmente relevante, al menos nada sociológicamente fuera de lo común, si no fuera porque Bourdieu explora el cúmulo de contradicciones y expectativas defraudadas a las que ha llegado la conciencia de los entrevistados sin imponer una definición previa ni sociocéntrica de las antinomias o los problemas. Como si tiraran pacientemente de un ovillo enredado, Bourdieu y sus colaboradores se detienen en el proceso histórico y biográfico que lleva hasta el momento actual, en el conjunto de las condiciones socioeconómicas que estructuran la conciencia de los entrevistados, en la conjunción y entrelazamiento de ambos. De esa manera y no de otra, cabe la posibilidad de diseñar un programa de intervención y de ayuda racionales que tenga en cuenta las razones, necesidades y resistencias de las conciencias de los más apartados.

\section{LA MITAD SOMETIDA}

Solamente comprendiendo la paradoja de la doxa es posible entender cómo la mitad de la humanidad, las mujeres de todas las culturas y gru-

21 En una reciente entrevista mantenida por Pierre Bourdieu con Günter Grass tras la concesión del Premio Nobel de Literatura a éste último, declara el escritor alemán: "En La miseria del mundo usted y sus colaboradores han conseguido establecer el concepto de entendimiento, no del sabelotodo: una visión de las condiciones sociales en Francia que es enteramente trasladable a otros países. Sus historias me seducen como escritor, para utilizarlas como material bruto..." (BOURDIEU y GRASS 1999:1) 
pos sociales, han estado sometidas e, incluso, conniventemente sometidas, a los intereses, razones y principios masculinos. Un trabajo sociológico seriamente liberador no sería tal si no abordara y aislara en un momento $\mathrm{u}$ otro los principios androcéntricos de nuestra civilización y no indagara los motivos por los que la conciencia femenina ha quedado histórica y espontáneamente relegada a aquélla. La dominación masculina (Bourdieu 1998e) practica una arqueología de los principios de visión, división y dominación masculinos o, más bien, de cómo unos principios histórica y contingentemente generados pasan por ser principios naturales y absolutos, de cómo los hombres asumen culturalmente su papel de virilidad dominadora y de cómo las mujeres corporeizan su papel de sumisión femenina.

La experiencia dóxica es la de la aceptación espontánea del orden y el sentido de las cosas tal como se presentan y las hemos conocido, algo que la etnometodología y la fenomenología han explorado con detenimiento; más aún, las experiencias de la conciencia, que casi todos los científicos sociales estarían dispuestos a afirmar que son exclusivamente un dominio de las estructuras cognitivas, son, antes que nada, disposiciones del cuerpo. De ahí que, la sumisión, el acatamiento, el recogimiento, la vergüenza y el rubor, el desvelamiento calculado, sean tanto atributos culturales de la femineidad como manifestaciones corporales espontáneas de una mujer, manifestaciones culturalmente aprendidas y socialmente generadas que al haberse transmutado en manifestaciones corporales acaban por ser percibidas y comprendidas como manifestaciones naturales de la mujer. Síntoma evidente de que es en el cuerpo y en sus disposiciones donde se depositan y activan las estructuras de la conciencia, es que en los países donde las mujeres están más sometidas y controladas, sea el cuerpo el primero que sufra el ataque y la ira de los que desean reprender ese instinto supuestamente natural, femenino y pecaminoso al mismo tiempo: ocultar el cuerpo, esconderlo, maltratarlo, afearlo, restringirlo a su función reproductora, revestirlo de tabúes —menstruaciones contaminantes, miradas potencialmente devastadoras...-, dominar, en pocas palabras, una "naturaleza irredenta" que puede poner en peligro la masculinidad, un giro políticamente maestro que hace pasar una relación social y cultural de dominación por un principio natural de diferenciación.

Nada de esto sería tan tremendamente efectivo si una de las mitades implicadas en la relación de dominación no la asumiera y respetara tan completamente: los principios de percepción, pensamiento y acción con los que están dotadas las mujeres son, en primer lugar y sobre todo, principios de visión y división sociales, de manera que las mujeres no incorporan otra cosa que unos principios de percepción de sí mismas 
culturalmente androcéntricos y, por tanto, acatan naturalmente los rasgos distintivos de femineidad y sometimiento social que desde la visión masculina preponderante se supone que deben asumir. Romper con ese círculo dóxico de autopercepción es, de forma espontánea e indeliberada, imposible. La sumisión es automática, está sólidamente establecida sobre un conjunto de evidencias compartidas e incorporadas, y se manifiesta maquinalmente en los gestos, ademanes y posiciones que adoptamos ${ }^{22}$.

La misión de la sociología en este caso es evidente: la sumisión dóxica a un orden social establecido, a una relación de dominación entre los sexos, no puede romperse si no existe ni siquiera la conciencia $-\mathrm{O}$, cabría decir, si no hay posibilidad alguna de que aflore esa conciencia-, de que la desigualdad no es natural, por mucho que los atributos físicos nos diferencien superficialmente ${ }^{23}$; la misión de la sociología es triple: primero, proporcionar esos elementos de reflexión, desvelar los mecanismos dóxicos del pensamiento y, de paso, la artificialidad de lo supuestamente natural ${ }^{24}$; segundo, proporcionar proyectos realizables de emancipación, modelos alternativos y concebibles de comportamiento sexual; tercero, apoyar los movimientos actuales capaces de retar al orden más estable y

22 “...estamos condenados a encerrarnos en una de las antinomias más trágicas de la dominación simbólica: ¿cómo revelarse contra una categorización socialmente impuesta sino a través de una categoría construida según esta categorización, y haciendo así existir las clasificaciones y las restricciones a las que pretende resistirse (en lugar, por ejemplo, de combatir por un orden sexual nuevo en el que la distinción entre los diferentes estatutos sexuales fuera indiferente)?" (BOURDIEU 1998e: 131). También: "...los dominados aplican a lo que les domina los esquemas que son el producto de la dominación o, en otros términos, su pensamiento y sus percepciones están estructurados conforme a las estructuras mismas de la relación de dominación que les es impuesta, sus actos de conocimiento son, inevitablemente, actos de reconocimiento, de sumisión (BOURDIEU 1998e: 19).

23 En varias ocasiones Bourdieu ha contrariado a la teoría psicoanalítica que tiende, siempre, a naturalizar todas las categorías del ser y el pensar, teoría que se remite permanentemente a unas categorías diferenciadas y preexistentes que explican el estado actual de las cosas. En contra de esa posición Bourdieu a abogado siempre, con Foucault, por una "rehistorización de la sexualidad" (véase Bourdieu 1998e: 110).

24 En contra de Lipovetsky y otros filósofos posmodernos, que siguen argumentando que uno u otro tipo de comportamiento es resultado de una elección voluntaria (véase LIPOVETSKY 1999a y 1999b) y que, por tanto, basta con quererlo para superarlo o alterarlo, Bourdieu enraíza esas diferencias en las disposiciones corporales aprehendidas y aprendidas que son el resultado de la incorporación inevitable de estructuras de visión y división sociales. En esto, el pensamiento posmoderno es especialmente cándido e iluso cuando no regresivo. Lipovetsky dice: ala mujer seduce a través del físico y el hombre a través del humor, y esos son códigos escogidos libremente en una sociedad igualitarian (LIPOVETSKY 1999b: 1). 
duradero de la historia, el androcéntrico, movimientos homosexuales que al mostrarse públicamente, se evaden de la categorización negativa a la que han estado sometidos y que les había condenado a la inexistencia, retando el tabú sagrado de la feminización de lo masculino ${ }^{25}$.

Se ha dicho ya en varias ocasiones durante los últimos años que la verdadera revolución del siglo que acaba ha sido la de la larga y dura liberación femenina, y la sociología debe contribuir, más explícitamente que nunca, tal como hace La dominación masculina, a que el movimiento liberador alcance su plenitud. No se trata de una demonización de lo masculino ni de una exaltación del feminismo radical: la mirada compasiva del sociólogo descubre la merma y disminución que supone el estar encerrado en las exigentes evidencias de la masculinidad -el miedo permanente del hombre a no estar a la altura de las leyes implícitas de la hombría-, el empobrecimiento afectivo, social y sentimental que conlleva estar dominado por el poder viril de dominar, pero también, por otra parte, el desquiciamiento que supone para muchas mujeres el acabar reproduciendo en tantos casos los patrones de comportamiento masculinos para demostrar y demostrarse que pueden ser como los hombres.

Una sociedad más libre e integradora provendría, sin duda, de que cada uno de los sexos pudiera librarse de las imposiciones que, cada uno a su manera, tiene que soportar, y la sociología puede hacer y decir mucho en esa dirección.

\section{LA NECESIDAD DE UTOPÍAS Y LA CONSTRUCCIÓN DEL ESTADO EUROPEO}

Para construir el Estado europeo, se debe renunciar a los Estados nacionales. Esto es evidente, pero sólo los Estados nacionales pueden construir el Estado supranacional. ¿Cómo se puede influir en los Estados singulares? ¿Cómo se puede tratar con los Estados singulares para que abandonen la competencia directa y miope y se integren en un proyecto colectivo en el que se añadan los mejores valores de cada una de las naciones? (Bourdieu 1999c:1)

Estas palabras fueron pronunciadas por Pierre Bourdieu con ocasión de un encuentro titulado Reformulación de una posición izquierdista, más

25 Recuérdese, por ejemplo, la ya mítica y multitudinaria manifestación anual de la Love Parade o los días del orgullo gay en los que se sale provocadoramente del anonimato cotidiano y, sobre todo, de la posible y probable vergüenza con que se vive la homosexualidad, para reclamar presencia y existencia públicas y satisfacción por ser lo que se es. 
allá de la izquierda y la derecha ${ }^{26}$ en el que participaron, además de él, Ulrich Beck, el sociólogo alemán contemporáneo más sólido, y Joschka Fischer, ministro de exteriores alemán y miembro del partido de Los Verdes. Como resulta evidente tras la lectura del título, más allá de terceras vías aparentemente alternativas a las políticas neoliberales, los tres intervinientes buscaban los fundamentos de un programa transnacional -político, económico, sindical, intelectual- capaz de contrarrestar los efectos desintegradores de la globalización económica y capaz de ofrecer una alternativa a un Estado europeo dominado por criterios exclusivamente tecnocráticos.

Poco antes de esa reunión Pierre Bourdieu había intervenido en un encuentro cultural franco-alemán en la Universidad de Freiburg con una dura y polémica conferencia titulada $E l$ pensamiento Tietmayer $^{27}$ en la que denunciaba cómo bajo el cúmulo de eufemismos que conforman el lenguaje económico actual, se escondía el claro propósito de desmantelar las más altas adquisiciones de la civilización occidental. Frase a frase, tomando como referente la entrevista que previamente había concedido Tietmayer al diario francés $L e$ Monde ${ }^{28}$, Bourdieu va desmontando y desvelando lo que la jerga economicista pretende hacer pasar por diagnóstico único de la realidad. Como ejemplo de la confrontación, valga mencionar:

Tietmayer: "la apuesta hoy por hoy es la de crear las condiciones favorables para un crecimiento duradero y la confianza de los inversores. Hace falta controlar los presupuestos públicos...”

${ }^{26}$ El encuentro se celebró en el mes de julio del año 1997 y tuvo como título el de Reformulierung einer linken Position jenseits von links und rechts (Reformulación de una posición izquierdista más allá de la izquierda y la derecha). Las conferencias que compusieron ese encuentro fueron, por parte de Pierre BourdiEU, "Gegen die Brüsseler Technokraten", "Der Beitrag der Intellektuellen" y "Gegen das Maastricht-Europa"; por parte de Ulrich BECK, "Demokratische Re-regulierung" y "Die Bedeutung von transnationalen Institutionen"; por parte de Joschka FISCHER, "Der Euro als Chance für eine europäische Diskussion" y "Der Neoliberalismus ist eine Wertentscheidung".

27 Hans Tietmayer fue presidente del autónomo y todopoderoso Bundesbank alemán. Desde ese pedestal, Tietmayer ha sido uno de los adalides del desgüace del Estado del bienestar en aras de la estabilidad macroeconómica. Originalmente escrito en francés, el artículo fue publicado primero, sin embargo, en el semanario alemán Die Zeit el 1 de noviembre de 1996, p. 2, con el título "Warnung vor dem Modell Tietmayer. Europa darf sich den neoliberalen Theorien des Bundesbankpresidenten nicht unterwerfen" (1996b). Más adelante apareció en francés bajo el título "La pensée Tietmeyer" (1998f). Ambos textos presentan, sin embargo, pequeñas variaciones fruto de su adaptación al medio y al tipo de público al que iban dirigidos.

28 La entrevista fue publicada el 17 de octubre de 1996. 
Bourdieu: "Es decir —será más explícito en sus siguientes frases-, enterrar lo más a prisa posible el Estado social y, entre otras cosas, sus políticas sociales y culturales dispendiosas..."

Tietmayer: "reformar el sistema de protección social..."

Bourdieu: "Es decir, enterrar el wellfare state y sus políticas de protección social, hechas para arruinar la confianza de los inversores, para suscitar su legítima desconfianza, seguros de que sus adquisiciones - hablamos de adquisiciones sociales y podemos hablar seguramente de adquisiciones económicas-, yo diría sus capitales, no son compatibles con las adquisiciones sociales de los trabajadores...

Más que de la relectura irónica y desveladora de las palabras del gobernador del banco alemán, de lo que se trataba, sin embargo, era de advertir que el fundamento del nuevo Estado europeo no podía ser el de un conglomerado de naciones sometidas a los dictados del Bundesbank o cualesquiera otro organismo financiero internacional. De lo que se trataba, claro está, es de no sucumbir ante el empuje y la injerencia de la lógica economicista más descarnada (una versión siempre parcial y empobrecida de la lógica económica que es mucho más compleja y variada) que intenta imponer sus criterios heterónomos de razonabilidad a todos los campos del espacio social. Se estaba hablando, sobre todo, de lo que estaba en juego para Europa y, de paso, para aquellas naciones que tomaban los logros sociales de la civilización occidental como ejemplo a seguir:

Un Estado así debería ser relativamente independiente respecto a las presiones de las fuerzas económicas y la presión de los intereses nacionales (en especial en cuanto al trabajo). Contra una Europa de los Bancos, contra una Europa del Bundesbank, contra la Europa de Hans Tietmayer, no hay ningún otro medio que el de la creación de un welfare state, tan rápido como sea posible, mediante la movilización de todas las fuerzas progresistas capaces de enfrentarse a las falsas alternativas que pretenden imponérseles —entre un verdadero nacionalismo y un falso internacionalismo que sólo es la máscara de un verdadero imperialismo(Bourdieu 1996b:2).

Muchos periodistas y adversarios académicos y políticos aprovecharon esta ocasión para acusar a Bourdieu —que, dicho sea de paso, al entrar de lleno y conscientemente en la esfera pública es objeto de toda clase de descalificaciones- de estatalista, de valedor de fórmulas políticas trasnochadas, de conservador reaccionario que añora la figura de un Estado protector. Debemos contemplar el reverso de estas críticas, sin embargo, para llegar a desvelar su verdadera intención y contenido. En la conversación mantenida por Grass y Bourdieu en el mes de diciembre del año 99, comenzaba manifestando el primero: 
Grass: ...nunca hubiera pensado que yo, un día, tuviera que pedir más Estado. Siempre tuvimos en Alemania demasiado Estado, sobre todo demasiado Estado del orden. Ahora caemos en el otro extremo. El neoliberalismo, sin querer tener que ver con ideología alguna, ha tomado posesión del sueño del anarquismo, desmontar el Estado, desplazarlo a un margen. Afuera con él, ya nos encargamos nosotros. Si hoy tiene que acometerse un cambio necesario en el camino de la reforma, no pasa nada, lo mismo en Alemania que en Francia, si la industria y la economía no lo aprueban. Los anarquistas hubieran podido soñar con esta enajenación del poder, y así me encuentro yo -y seguramente usted también-, en la curiosa situación de procurar que el Estado vuelva a asumir sus responsabilidades e intervenga en la regulación.

Bourdieu: Es a esa inversión, exactamente, a la que yo me refería. Pero, ¿podemos contentarnos con pedir "más" Estado? Para no quedar atrapados en las redes de una revolución conservadora, debemos reflexionar sobre la manera de inventar un nuevo Estado (Bourdieu y Grass 1999: 46).

No se trata, por eso, de un simple retorno a fórmulas estatalistas sino, más bien, de proyectar las nuevas bases de un Estado paneuropeo que no es el de los bancos centrales, el de la tecnocracia de Bruselas o el de la patronal industrial; se trata de recuperar los valores más propios de la ilustración europea, los logros sociales del siglo $\mathrm{xx}$, es decir, los valores más plenamente universales, e integrarlos en un proyecto internacional conjunto, en el que lo político y lo social primen sobre lo económico y en el que los intelectuales sean permanentemente la voluntad y la voz crítica capaz de denunciar los desvíos interesados y arteros de grupos de interés particulares. No se trata, simplemente, por eso, de una cuestión o de una decisión, como la lógica simplista del periodismo quiere, entre Europa sí o Europa no, sino de desmontar esa pregunta y contestar, primero, a "qué se entiende por Europa si Europa fuera lo que da a entender el Tratado de Maastricht" (Bourdieu 1997d: 2).

Para que no quede resquicio de duda:

Estoy a favor de Europa, por una Europa social en la que no jueguen tan sólo las fuerzas del mercado. Esta Europa debe ser construida inmediatamente. Debemos hacer presión porque creemos en Europa, porque queremos Europa. Como ciudadano debo luchar para que haya una Europa bajo determinadas condiciones (seguridad social, derechos humanos, protección de los trabajadores, derechos de los emigrantes, limitación del tiempo de trabajo a 35 horas, etc.). Todos esos debates deben tener lugar al mismo tiempo. El fatalismo determinista, como el que se expresa a través de Tietmayer, de que alcanzaremos la unión monetaria de la que se derivará la futura y maravillosa Europa, es una deducción falsa (Bourdieu 1997d: 2).

Como en el resto de los frentes cle su trabajo, el éxito de toda la iniciativa pasa por actuar más allá de los límites de las fronteras naciona- 
les, por internacionalizar la reflexión, por fundar una utopía común y universalista, por sacudirse el lastre que representa el neoliberalismo y los gobiernos que lo asumen - cuya estrategia principal es presentar y representar a las utopías como caducas o sobrepasadas o, como dijo en otra parte, por establecer la nueva utopía de una explotación sin límites (Bourdieu 1998g) —, para la toma de una posición política eficaz y activa.

\section{EL EFECTO DE LA TELEVISIÓN: UNA FUERZA DE BANALIZACIÓN}

Sobre la televisión (1997c), uno de los libros más comentados y peor entendidos de Bourdieu, tiene como intención principal la siguiente ${ }^{29}$ :

Pienso, en efecto, que la televisión, a través de los diferentes mecanismos que intento describir de forma sucinta - un análisis profundo y sistemático habría exigido mucho más tiempo-, pone en muy serio peligro las diferentes esferas de la producción cultural: arte, literatura, ciencia, filosofía, derecho; creo incluso, al contrario de lo que piensan y lo que dicen, sin duda con la mayor buena fe, los periodistas más conscientes de sus responsabilidades, que pone en un peligro no menor la vida política y la democracia (1997c:7-8).

No se trata de que el medio televisivo o periodístico sea intrínsecamente perverso o manipulador ${ }^{30}$. Se trata, más bien, de las coacciones a las que está sometido el medio y sus profesionales y al uso desviado que de aquél se hace: los periodistas tienen la manía y la propensión a marchar y presentarse inmediatamente allí donde, supuestamente, está la noticia, al escenario donde se está produciendo, a la retransmisión viva o

29 La brevedad del texto y el tema tratado animaron a más lectores de los habituales a asomarse al trabajo de Bourdieu. Leído de manera aislada, sin conocimiento del resto de la obra de Bourdieu, de su pensamiento ni de sus intenciones concretas, este libro puede tomarse, como han hecho alguno críticos periodísticos, como un texto menor o endeble. La intención del texto es, evidentemente, polémica, y toma partido, como en pocas ocasiones lo ha hecho, por hacer accesible a un público mayoritario un tema que podría haber abordado, evidentemente, con otra perspectiva o profundidad. El libro comienza diciendo, precisamente: "He decidido ofrecer por televisión estas dos conferencias para tratar de ir más allá de los límites de la audiencia normal de un curso del College de France [...] un análisis profundo y sistemático habría exigido mucho más tiempo" (1997c: 7).

30 Otros autores opinan, abiertamente, que la televisión y la saturación de imágenes e información de cualquier medio audiovisual "destruyen más saber y más entendimiento del que transmiten" (SARTORI 1998: 12) y, en cuanto a la formación del juicio y el discernimiento políticos, "actualmente, el pueblo soberano "opina" sobre todo en función de cómo la televisión le induce a opinar" (SARTORI 1998: 66). 
en directo del acontecimiento, a la búsqueda del testimonio o el padecimiento de quien ha experimentado lo ocurrido. Tal comportamiento y certeza están basados sobre una ficción difícil de corregir: que la explicación de lo que ha sucedido se encuentra allí donde eso mismo haya ocurrido, que las razones que nos ayudan a comprender por qué ha comenzado o progresado tal hecho, están en el mismo sitio donde pueden observarse sus efectos o manifestaciones, y que los más competentes para aclarar las razones de lo visto son los que lo han presenciado, los que estaban cerca. No hace falta insistir demasiado en la puerilidad y simpleza de esta certeza, porque si algo saben las ciencias sociales es, desde luego, que la verdad de algo no reside nunca, exclusivamente, en el escenario, y que los protagonistas no poseen todos los resortes que explican su propio comportamiento. Esa convicción periodística está fomentada y cultivada, sobre todo, por la lógica de la primicia o la exclusiva, otra ficción especialmente perniciosa: no cabe la reflexión sosegada sobre las razones de lo sucedido sino, todo lo contrario, la carrera apresurada de un fogonazo a otro, la sucesión de crónicas yuxtapuestas retransmitidas desde el punto álgido, la velocidad y la anticipación como uno criterio de medición del valor de la noticia. Hasta tal punto impera esta lógica, y hasta tal extremo obliga la inercia del campo periodístico a trabajar de esa manera, que cuando no hay noticia es necesario provocar, crear o generar la noticia, bien mediante el interrogatorio a cualquier transeúnte desprevenido que, desde luego, nunca posee las claves para responder a lo que le preguntan, bien mediante la persecución de lo más sensacionalista, más espectacular, más abyecto, más dramático. Todo vale para que lo emitido sea, simultáneamente (y supuestamente) exclusivo, aunque, seguramente, sería mejor decir irrepetible, porque es cierto que cada suceso es en sí mismo único e irreproducible, y es esa rareza la que le proporciona - hoy, según la televisión - su valor, su calidad. Ocurre, claro, que todas las primicias y exclusivas tienen el mismo aire, manipulan los mismos temas, ejecutan puestas en escena similares. La lógica de la competencia entre medios audiovisuales provoca una emulación que no hace falta que sea consciente y explícita para que sea patente y meridiana. La búsqueda de la diferencia, paradójicamente, provoca la homogeneización, la repetición, la banalización: el corresponsal, el enviado, muestra, efectivamente, lo que debe ser mostrado, pero lo esencial pasa siempre inadvertido, queda oculto tras la dramaturgia de las imágenes, y la noticia acaba tomando un sentido que, en vez de aclarar la realidad mostrada, la sume en un estado de confusión e indiferenciación amorfo. Y esa lógica se exacerba y se convierte en único principio de funcionamiento del campo periodístico, porque no hay otro criterio de éxito 
y buen hacer profesional que el del índice de audiencia: la magnitud suplanta y justifica, se erige en medida canónica a partir de la que calcular y ponderar el valor de una transmisión, de una noticia, de una intervención, de un programa, $\mathrm{y}$, de nuevo, haciendo buenas las propiedades de la lógica circular, el incremento de la audiencia necesita de una puesta en escena cada vez más dramática que capta más televidentes que necesitan un pathos cada vez más intenso, en una espiral sin ninguna resolución más que la de la continua espiral.

No tiene por objeto esta crítica la de demonizar a la profesión periodística o a la de los medios de comunicación, tan necesarios. Se trata de desvelar, de desvelarles, las censuras implícitas o explícitas, desconocidas o asumidas, ignoradas o sufridas, rechazadas o queridas, que gobiernan el funcionamiento del campo periodístico y, por tanto, de su profesión y de su manera de ejercer esa profesión y de las repercusiones enteramente políticas que ese ejercicio preciso entraña. Se trata, sobre todo, de despejar y enseñar la fuerza formidable de la injerencia de principios ajenos, propiamente, al campo - principios desnudamente económicos-, que imponen constricciones feroces y formas de actuar.

No vale con pensar, con pensarse, como muchos periodistas quieren, que la profesión periodística, que el mero hecho de ser periodista, garantiza la libertad respecto a toda constricción sociológica, económica, que la mera convivencia con lo que se llama actualidad es garantía de una transmisión fidedigna de los hechos, que una mera afirmación de independencia periodística es garantía de verdadera libertad. Sólo puede redundar en beneficio de los propios periodistas el que sean conscientes de los determinantes que constriñen su profesión. Y lo mismo vale para los invitados de los espacios televisivos, intelectuales en demasiados casos de escaso rigor, que acumulan capital simbólico sin apenas esfuerzo, al precio de convertirse en fast thinkers, obligados por las censuras temporales de los programas a los que asisten a opinar sobre cualquier tema en el menor de los tiempos posibles, a reproducir fórmulas agotadas o lugares comunes, a hacer todo lo contrario del ejercicio más propio de un intelectual, que es el de tomarse tiempo para distanciarse de una situación, para pensarla. También a esta clase de intelectuales mediáticos, incapaces de comprender que, al contrario de como se piensan así mismos, carecen por completo de libertad, les beneficiaría una reflexión sobre las censuras y constreñimientos a los que les somete la televisión, única manera de escapar a esas mismas censuras y constreñimientos.

Bourdieu se expuso con toda conciencia, con la redacción de este libro, a las críticas y mal entendimientos por parte de la crítica. Sobre la televisión es, probablemente, su libro más asequible, más conscientemente 
divulgativo, más voluntariamente dirigido a convertirse en un instrumento de reflexión e intervención. Si de lo que se trata es de extender el acceso de la ciudadanía a los valores más universales, de proporcionar los medios objetivos para que sean capaces de tomar la palabra en sociedad y formular políticamente su visión de la sociedad, sus problemas y necesidades, y si la televisión ha decidido tomar la vía de la banalización y trivialización del lenguaje político, de los asuntos sociales, no es extraño que Bourdieu haya decidido tomar a la televisión como objeto de estudio, como objeto del que se deben desvelar sus dependencias y funcionamiento.

\section{LA ARENA PÚBLICA}

Hay una diferencia reseñable entre el Bourdieu de los últimos años y el dedicado, en décadas anteriores, a una labor más estrictamente académica. Bourdieu había defendido en varias ocasiones que la manera más propia del intelectual para intervenir en la sociedad es la de acumular el suficiente capital intelectual y simbólico en su propio campo como para participar en la vida pública y política sin sombra de interés partidista $o$ de dependencia sectaria. Parece como si, después de cuarenta años de trabajo y dedicación, de independencia y del ejercicio comprometido de la sociología reflexiva - de saberse situado en un determinado punto del espacio social e intelectual, condicionado y propiciado, al mismo tiempo, por una serie de determinantes, a decir lo que dice y a pensar lo que piensa-, hubiera reunido la suficiente convicción moral y determinación ética para intervenir en los asuntos públicos, para dejarse entrevistar - son relativamente frecuentes las que ha concedido en los últimos tiempos-, para aparecer, incluso, en programas de televisión, para escribir en la prensa, para pronunciarse públicamente por un tipo concreto de sociedad y de Estado.

Tomar el riesgo - asumido por razones políticas - de esta vulgarización, ha sido para Bourdieu aceptar renunciar a las garantías del rigor relativo del debate científico para adentrarse en un terreno donde se permiten todos los golpes (Bourdieu y Bourmeau 1997:22)

Exponerse públicamente es, evidentemente, ocasión de ser visto y atacado, y esta exposición pública, probablemente, alcanzó su cenit el 12 de diciembre de 1995, en la Gare de Lyon,, cuando Bourdieu se dirige a los trabajadores franceses en huelga de esta manera: 
Estoy aquí para expresar nuestro apoyo a todos aquellos que luchan, desde hace tres semanas, contra la destrucción de una civilización asociada a la existencia del servicio público: civilización de la igualdad republicana de los derechos, a la educación, a la salud, a la cultura, a la investigación, al arte y, por encima de todo, al trabajo (Bourdieu 1995b: 1)

Una reivindicación en términos tan elementales, absolutamente consecuente con un esfuerzo tenaz, coherente y continuado de preservación del tipo de civilización occidental que, por primera vez en la historia de la humanidad, tendía a garantizar $\longrightarrow$, al menos, a instrumentar los controles legales y administrativos para que, paulatinamente, eso pudiera ocurrir- un acceso igualitario y universal a cierta clase de derechos, provocó, y sigue provocando, toda clase de reacciones airadas y contrarias. La prensa francesa, desde Le Monde ${ }^{31}$, pasando por Le Nouvel Observateur ${ }^{32}$ y terminando por el Magazine Littéraire ${ }^{33}$ y Esprit ${ }^{34}$, han prorrumpido en

31 El 28 de agosto de 1998 aparecieron en este periódico varios artículos relacionados con Bourdieu y su obra: "Des infortunes de la vertu scientifique", de Bernard Lahire; "La culture des paradoxes"; "Des idées et des outils", de Patrice Pinell; "Bourdieu et la contradiction", de Patrick Kechichian; "Le cas Bourdieu en examen", de Michel Contant. Este último dice en un momento del desarrollo de su artículo: "Un ataque tan virulento no se hubiera producido si Bourdieu no se hubiera radicalizado políticamente y no hubiera atacado frontalmente a eso que él llama la invasión neoliberal. Y así es: el precio de utilizar las herramientas sociológicas en la lucha política es el de la descalificación global.

32 La edición de Le Nouvel Observateur es del 3 al 9 de septiembre de 1998, n. ${ }^{\circ}$ 1765 y lleva por título general "Bourdieu: les couacs de l'imprécateur".

33 El número 369 de octubre de 1998 de Le Magazine Littéraire, estuvo dedicado a la figura de Pierre Bourdieu con el ambivalente título de: "Pierre Bourdieu. L'intellectuel dominant?". Los artículos que componían el dossier son: RAYNAUD, Philippe. "Le sociologue et "sa" philosophie"; "Bourdieu en 20 dates"; Colas, Dominique. "Le Marx de Bourdieu, de la continuation à la rupture"; MONOD, Jean-Claude. "Heidegger et la hauteur philosophique"; Dollé, Jean-Paule. "Histoires de domination"; CorcuFF, Philippe. "Lire Bourdieu autrementw; BonNEWITZ, Patrice. "Entre enthousiasme et contestation"; DE SINGLY, Françoise. "Le sociologue et l'éducation"; MEIRIEU, Philippe. "Bourdieu pédagogue"; DE BIASI, Pierre-Marc. "Esthétique: les batailles pour l'hégémonie"; MARTEL, Frédéric. "Didier Besase: la Misère du monde au théâtre, propos recueillis"; BougnOUx, Daniel. "Face à l'ogre audiovisuel"; Mossuz-LavaU, Janine. "Dominants et dominées"; MARTEL, Frédéric. "Bourdieu et la question homosexuelle"; GRIGNON, Claude. "La raison de plus fort"; MARTEL, Frédéric. "Jeannine Verdès-Leroux: contre Bourdieu"; Mongin, Olivier. "Les impasses du politiquen; BENSAÏD, Daniel. "Désacraliser Bourdieu"; "Sur Bourdieu".

34 El número de Esprit de julio de 1998 llevaba como título principal "Le populisme facon Bourdieu ou la tentation du mépris". Olivier Mongin, redactor jefe, argumenta: "Es exacto que se diseña un espacio populista de izquierda en el que Bourdieu desearía ser el maestro haciendo desaparecer las fronteras entre la violencia política y el rigor pseudointelectual...". 
una salva unánime de críticas contrarias y descalificaciones globales ${ }^{35}$. En ese mismo exceso emocional común, más espontáneo que meditado, está contenida la verdad de sus declaraciones: el insulto no es crítica científica ni una contrastación empírica de los conceptos construidos a lo largo de décadas que desvelan, por ejemplo, cómo funciona el campo periodístico y a qué censuras, fuerzas y servidumbres están sometidos quienes están inmersos en ese campo. El insulto, en todo caso, es expresión del malestar de un conjunto de intelectuales, políticos y periodistas que se revelan contra el análisis científico de sus vidas, que se resisten a creer que muchos de sus actos y decisiones dependen, antes que nada, de un conjunto de fuerzas sociológicas inaprehensibles, que no pueden soportar el enfrentarse a los principios elementales que rigen su comportamiento. No ha habido un ápice de rivalidad científica en toda la literatura generada en los dos últimos años, desafortunadamente, y sí mucha antipatía sociológica y política ${ }^{36}$.

Nadie, en ningún sitio, ni Bourdieu ni ninguno de las personas que trabaja con él, ha defendido nunca que los conceptos utilizados en sus trabajos para intentar comprender y describir la economía de las prácticas sean construcciones acabadas de una vez para siempre. Muy al contrario, Bourdieu suele citar a Wittgenstein, un párrafo de Los cuadernos azul y marrón:

35 La crítica, por llamarla de alguna manera, más carente de sentido que se le ha hecho a Bourdieu, proviene de un periódico español: el 9 de enero de 1999 La Vanguardia publicó un artículo titulado "Pensador de guardia francés", en el que la insolencia de los comentarios es sólo paralela a la ignorancia del comentarista: "Pero nada envejece antes que la moda, y Levy [se refiere a Bernard Henry Levy] perdió su silla, la que ahora ocupa quien en este sentido es ya un sofisticado producto de síntesis: prestigio académico, pensamiento débil (así lo atestiguan sus libros sobre la televisión y la condición femenina) y "look" equidistante entre el punto batracio de Sartre y el de príncipe valiente de Levy: en sus fotos junto a los "sans abri" y los "Sans papiers" luce como un sindicalista solidario, bonachón y medio guapo". El autor de este panfleto de urgencia y encargo, un tal Moix, encabezaba el artículo diciendo "el cargo, virtual a efectos oficiales, es anhelado por todo intelectual con afán de notoriedad" aunque, más bien, haya sido su afán de sobresalir en el bronco campo periodístico el que, al mínimo precio de ridiculizar cuarenta años de trabajo que desconoce y no comprende, le ha llevado a redactar esas líneas.

36 La invalidación total del trabajo y las teorías de Pierre Bourdieu encuentran su más elaborada expresión en el libro de Jeannine VerDÈs-Leroux, Le savant et la politique, que no duda en denominar a la sociología practicada por Bourdieu como "terrorista". La sociología de Bourdieu no sería otra cosa que un entramado de opiniones, de prejuicios, de gustos y disgustos, de opciones filosóficas y de juicios morales disfrazados de saber. Los resultados de su trabajo serían pobres y escasos, su método incierto, sus interpretaciones de los datos estadísticos falaces, sus descubrimientos, las evidencias utilizadas y sus proyectos, irrealizables por su desmesura. 
Somos incapaces de transcribir claramente los conceptos que usamos; no porque no sepamos su auténtica definición, sino porque no tienen una auténtica "definición". El supuesto de que deben de tener una definición así, sería como el supuesto de que niños que juegan al balón, juegan fundamentalmente según unas reglas estrictas (Wittgenstein 1970: 49).

Es decir, el exceso de formalización propio de la mayoría de las ciencias sociales distorsiona por completo el objeto que estudia, más aún cuando se trata de prácticas humanas. Por eso mismo, cualquier construcción sociológica no puede aspirar a durar permanentemente. Su naturaleza misma es el cambio, la constante puesta a prueba, el work in progress. Bourdieu mismo ha repetido en muchas ocasiones que no aspira a perdurar -al menos no por empecinamiento o por salvaguardar la posición o por hacer, simplemente, historia-, que a estas alturas de la historia de la teoría social es ridículo pensar en no ser sobrepasado gracias, precisamente, al uso, desgaste y perfeccionamiento de las herramientas conceptuales previamente creadas. Por eso, no es con el enfrentamiento mera y abiertamente político como se rebasará el trabajo de Bourdieu ni dejara de crear adeptos y gente fascinada por la hondura y comprehensividad de su trabajo, por la multitud de potencialidades que encierran sus conceptos y sus reflexiones. El hecho de que haya surgido una multitud de seguidores y emuladores más o menos cualificados, no merma un ápice el sentido de su trabajo; en todo caso, el de quien le imita o trata de emularlo. $\mathrm{Ni}$ siquiera el hecho de andar en el agudo filo que divide la tarea intelectual del compromiso político, el hecho de tomar partido por una causa $-\mathrm{y}$ en los últimos años, evidentemente, se han multiplicado- invirtiendo en ello el prestigio intelectual, acumulado en su tarea académica, justifican las censuras y las impugnaciones sin otros argumentos que los debidos a la propia posición - posición que se siente apelada, agredida, destapada, descubierta en lo que tiene de impostura y de protección de los propios intereses- desde la que se habla y se emiten esos juicios ${ }^{37}$.

Si cierno una y otra vez los mismos temas, si regreso repetidas veces a los mismos objetos y a los mismos análisis, es siempre, me parece, en un movimiento

37 Seguramente, de la cita siguiente entresacada de Méditations Pascaliennes, podría extraerse el principio que convenció al propio Bourdieu para aceptar esa implicación: "...si hay una cosa que nuestros filósofos, modernos y posmodernos tienen en común, más allá de los conflictos que les oponen, es la del exceso de confianza en los poderes del discurso. Ilusión típica del lector, que puede tener al comentario académico por un acto político o la crítica de textos por un acto de resistencia, y vivir las revoluciones en el orden de las palabras como revoluciones radicales en el orden de las cosas" (BOURDIEU 1997b: 10). ¿Quién de nosotros no se siente directamente apelado? 
en espiral que permite alcanzar en cada ocasión un grado de explicitación y de comprehensión superior, y descubrir relaciones desapercibidas y propiedades escondidas. "No puedo juzgar mi obra, dice Pascal, más que haciéndola; debo hacer como los pintores, debo alejarme de ella; pero no demasiado"... No sé si he tenido éxito, pero he alcanzado la convicción, en todo caso, de que el mundo social será mejor conocido, y el discurso científico sobre él mejor comprendido, si llegamos a convencernos de que no hay muchos objetos que sean tan difíciles de conocer, especialmente porque obsesiona los cerebros de aquellos que se aplican a su análisis, y porque esconde bajo las apariencias más triviales, las de la banalidad cotidiana para los diarios, accesible para el primer encuestador llegado, las revelaciones más inesperadas sobre lo que menos queremos saber de eso que somos (Bourdieu 1997b: 17).

Volver una y otra vez sobre los mismos temas, templando las herramientas ya forjadas, ahondar en el conocimiento del mundo social y en la manera en que conocemos ese mundo del que formamos parte, desentrañar sus intrincadas dificultades observando, sobre todo, las realidades más supuestamente triviales por cercanas y aparentemente conocidas, por escondidas o apartadas, por marginadas o acalladas para llegar a formarnos una idea de lo que es y debe ser el hombre y la sociedad en la que vive. Este es el legado de cuarenta años, y estas serán las líneas, gruesamente trazadas, de lo que confiamos todavía serán muchos años más ${ }^{38}$.

\section{BIBLIOGRAFÍA CITADA}

BOURDIEU, PIERRE. 1985. ¿Qué significa hablar? Economia de los intercambios lingüísticos. Madrid: Akal, 160 p.

- 1988. La distinción. Criterio y bases sociales del gusto. Madrid: Taurus, 598 p.

- 1991a. Die Intellektuellen und die Macht. Hamburg: VSA-Verlag, 124 p.

- 1991b. "Ich bin dazu da, die Intellektuellen nicht in Ruhe zu lassen", en Die Intellektuellen und die Macht: 13-32. Hamburg: VSA-Verlag.

- 1991c. "Der Korporativismus des Universellen. Die Rolle des Intellektuellen in der modernen Welt, en Die Intellektuellen und die Macht: 41-66. Hamburg: VSA-Verlag.

38 Este artículo, continuación de un primero escrito más ajustado a la explicación de la génesis, desarrollo, sentido y uso de los conceptos que componen el trabajo de Bourdieu, es deliberadamente menos "teórico" y más "político", en su tono y ritmo mismos. Se trata de hacer llegar al lector, en los encadenamientos y enlaces de temas propuestos, en la lectura planteada de los últimos años de trabajo, el registro más militante y partidista de sus escritos, si bien esto no quiere decir menos riguroso y preciso. El mismo título del artículo, "Pierre Bourdieu: del rigor académico a la rigurosa subversión", trata de desvelar la manera en que el capital académico, intelectual y simbólico acumulado durante décadas de trabajo está siendo empleado, sin perder un ápice de rigor o propiedad, en luchas propiamente políticas. 
- 1994. Libre echange. Paris: Éditions du Seuil / Les Presses du Réel, 148 p.

- 1995a Las reglas del arte. Génesis y estructura del campo literario, Barcelona: Anagrama.

- 1995b "Combatir a la tecnocracia en su propio terreno", publicado originalmente en Libération, 14 de diciembre de 1995. Puede encontrarse, también, en http://cariari.ucr.ac.cr/ oscarf/bourdieu2.html

- 1996a. "Störenfried soziologie. Zur Demokratie gehört eine Forschung, die Ungerechtigkeiten aufdeckt", Die Zeit, 21 de junio de 1996: 33.

- 1996b. "Warnung vor dem Modell Tietmayer. Europa darf sich den neoliberalen Theorien des Bundesbankpräsidenten nicht unterwerfen", Die Zeit, 1 de noviembre de 1996: 2.

- 1997a. "Pierre Bourdieu Editeur", Livres Hebdo, 244, 11-4-97: 40-41.

- 1997b. Méditations pascaliennes. Paris: Seuil, 316 p.

- 1997c. Sobre la televisión. Barcelona: Editorial Anagrama, 140 p.

- 1997d. "Gegen das Maastricht-Europa", Telepolis, http://www.heise.de/tp/deutsch/ special/pol/8037/1.html

- 1998a. "Die Demokratie braucht Soziologie", Die Zeit, 3 de abril de 1998: 1-3.

- 1998b. Contre-feux. Propos pour servir la résistance contre l'invasion néo-libérale. Paris: Raisons d'agir, Seuil, 126 p.

- 1998c. "Le mythe de la mondalisation et l'État social européen", en Contre-feux. Propos pour servir la résistance contre l'invasion néo-libérale: 34-50. Paris: Raisons d'agir, Seuil.

- 1998d. "Pour un nouvel internationalisme", en Contre-feux. Propos pour servir la résistance contre l'invasion néo-libérale: 66-75. Paris: Raisons d'agir, Seuil.

- 1998e. La domination masculine. Paris: Seuil, 146 p.

- 1998f. "La pensée Tietmeyer", en Contre-feux. Propos pour servir la résistance contre l'invasion néo-libérale: 51-57. Paris: Raisons d'agir, Seuil.

- 1998g. "Le néo-libéralisme, utopie (en voie de réalisation) d'une exploitation sans limites", en Contre-feux. Propos pour servir la résistance contre l'invasion néo-libérale: 108-119. Paris: Raisons d'agir, Seuil.

- 1999a. "Une révolution conservatrice dans l'édition". Actes de la Recherche en Sciences Sociales 126-127, mars: 3-28.

- 1999b. La miseria del mundo. Madrid: Akal, 564 p.

- 1999c. "Gegen die Brüseller Technokraten", Telepolis, http://www.heise.de/tp/deutsch/ special/pol/8031/1.html

- 1999d. "Gegen das Maastricht-Europa", Telepolis, http://www.heise.de/tp/deutsch/ special/pol/8037/1.html

Bourdieu, Pierre y Sylvain Bourmeau. 1997. "De l'anticonformisme a la subversion. Pierre Bourdieu. Quarante ans de travail éclairés par son nouveau livre: entretien exclusif avec un acteur majeur de la pensée contemporainen. Les Inrockuptibles 99, abril: 22-29.

Bourdieu, Pierre y Günter Grass. 1999 "Alles seitenverkehrt". Die Zeit 3 de diciembre de 1999: 45-47.

Contant, M. 1998. "Le cas Bourdieu en examen". Le Monde 28 de agosto de 1998.

CRIGNON, ANNE. 1998. "Lire Bourdieu ... 30 ans". Le nouvel Observateur 3 al 9 de septiembre de 1998, 1765: 10.

Derrida, JACQues. 1994. El País jueves 29 de septiembre de 1994: 34. 
ERIBON, DIDIER. 1998. "La reproduction du macho". Le nouvel Observateur 3 al 9 de septiembre de 1998, 1765: 9

FORRESTER, VIVIANE. 1996. El horror económico. Buenos Aires: Fondo de Cultura Económica, $166 \mathrm{p}$.

HaLimi, SERGE. 1997. Les nouveaux chiens de garde. Paris: Liber Raisons d'agir, Seuil, $112 \mathrm{p}$.

KÉCHICHIAN, P. 1998. "Bourdieu et la contradiction". Le Monde 28 de agosto de 1998. KRAUS, Karl. 1990. Escritos. Madrid: Visor, 200 p.

LAHIRE, B. 1998. "Des infortunes de la vertu scientifique". Le Monde 28 de agosto de 1998.

LEMIRE, LAURENT. 1998. "Un tag sur la statue". Le nouvel Observateur 3 al 9 de septiembre de 1998, 1765: 7-8.

LIPOVETSKY, GiLlES. 1999a. La tercera mujer. Barcelona. Anagrama.

- 1999b. "Bourdieu dice obviedades y el feminismo desprecia a la mujer". La Vanguardia, 13 de enero de 1999.

Malaurie, Gulllaume y Françors Bazin. 1998. "Bourdieu: les couacs de l'imprécateur". Le nouvel Observateur 3 al 9 de septiembre de 1998, 1765: 4-6.

Pinell, P. 1998. "Des idées et des outils", Le Monde 28 de agosto de 1998.

RODRÍGUEZ LÓPEZ, JOAQUín, 1993. "Introducción a la antropología general de Pierre Bourdieun. Revista de Dialectología y Tradiciones Populares XIVIII, 1: 7-46.

SARTORI, GIOVANNI. 1998. Homo videns. La sociedad teledirigida. Madrid: Taurus, $160 \mathrm{p}$. TABUCCHI, ANTONIO. 1997. "Discurso de apertura en el Parlamento Internacional de Escritores".

VERDÈS-LEROUX, JEANNINE. 1998. Le savant et la politique. Essai sur le terrorisme sociologique de Pierre Bourdieu. Paris: Grasset, 254 p.

WEITZMANN, MARC. 1997. "Engagement et déchirures”. Les Inrockuptibles 99: 42-44.

WitTGENSTEIN, Ludwig. 1970. Los cuadernos azul y marrón, Madrid, Tecnos. 